\title{
Physical features of reducing air pollution for the operating conditions of the drying drum of brick factories
}

\author{
Vadim Bespalov ${ }^{1 *}$, Gennadiy Turk ${ }^{1}$, and Oksana Gurova ${ }^{1}$ \\ ${ }^{1}$ Don State Technical University, 344022, 1 Gagarina sq., Rostov-on-Don, Russia
}

\begin{abstract}
The article is devoted to the study of the process of reducing air pollution in relation to the operating conditions of the drying drum of brick factories. The objectives of the work were to study and identify the physical characteristics of the process of reducing air pollution for the operating conditions of the drying drum of brick factories, for its subsequent effective implementation with the help of engineering systems. A block diagram is suggested of the physical model of the process of reducing air pollution for the considered production and technological conditions, revealing the relationship of a set of consistently and purposefully implemented stages of the cycle of dusting, using physical and energy concept as the theoretical basis. As a result of the study of the process of reducing air pollution, in relation to the operating conditions of the drying drum of brick factories operation, based on the analysis of possible solutions of the problem of dusting, physical features of the process of reducing air pollution for these production and technological conditions were identified for its subsequent effective implementation by means of engineering systems.
\end{abstract}

\section{Introduction}

The main factor affecting the level of working ability of employees, the level of labor productivity, and as a result, the growth of enterprise profits, is the creation of favorable working conditions. One of the necessary conditions for such work is the provision of standard values for microclimate parameters and dustiness of the air in the working areas of industrial premises and industrial sites. The problem of ensuring the normative values of the air parameters of the working areas of the drying drums of brick factories is very urgent, as it is determined by the increase in the types and severity of occupational diseases, poisonings, including acute ones, the number of accidents and industrial accidents. In modern conditions of intensification of production at the enterprises of the construction industry for the production of bricks, a high level of pollution of the air of industrial premises (internal task) and industrial sites (external task), leading to an active growth in allergic exacerbations and respiratory diseases, as well as an urgent need energy

\footnotetext{
*Corresponding author: izos-rgsu@mail.ru
} 
conservation brought to the fore the tasks associated with ensuring the normative state of air.

The author's analysis of possible solutions to the problem of dust removal [1-9] showed that for the operating conditions of the drying drum of brick factories in the air of working areas, dust concentration can be reduced on the basis of two main directions (cycles):

1. By reducing the dust-forming ability of clay and inert additives as feedstock, or a drying drum as technological equipment, which involves the development of a fundamentally new production and technological equipment for drying, as well as the improvement of the existing technological process organization drying, which would exclude the formation of inorganic dust with a $\mathrm{SiO} 2$ content by $20-70 \%$ and its release into the air (first cycle).

2. By reducing air pollution based on the implementation of additional special organizational measures, in combination with engineering systems, which would significantly limit the spread of dust aerosol as a dispersed system on an existing or planned drying drum as production and technological equipment followed by its destruction (second cycle).

At the same time, the effective implementation of the first cycle based on the process of reducing the dust-forming ability of clay and inert additives as a raw material, or a drying drum as techno-logical equipment, is due to the need to make changes to the technological process of drying clay and inert materials, as well as the need for changes in their basic physical and chemical properties, which may be due to a violation of technological regulations.

The ultimate goal of the implementation of the second cycle based on the process of reducing air pollution is the destruction of dust aerosol as a dispersed system. Therefore, at present, it is the second cycle that has found wide application to ensure standard values of dust concentration in the air based on the use of engineering dust suppression systems. Such systems can be effectively used in the case of successive rational organization of the binding of dust particles to each other, prevention of their distribution (localization) and removal directly from the formation zone, as well as purification of air (exhaust gases) from dust with its subsequent withdrawal to the air basin [10].

\section{Theory or experimental methods}

The process of reducing air pollution in general for the operating conditions of the drying drum of brick plants in a general form can be mathematically described as follows: where: $\mathrm{Pp}$ is the probability of implementing the process of reducing dust air pollution; $\mathrm{Pp} 1$ is the probability of implementing the process of reducing the dust-forming ability of clay and inert additives as a raw material, or a drying drum as a process equipment; Pp2 is the probability of the implementation of the process of reducing air pollution.

The physical model we have proposed for the process of atmospheric dust pollution for the operating conditions of the drying drum of brick plants is used as the basis for constructing a physical model of the process of reducing air pollution for the considered production and technological conditions. The block diagram of the physical model of the process of reducing air pollution for the dryer drum reveals the relationship of the totality of sequentially and purposefully implemented stages of the second cycle of dust removal of the atmosphere and is presented in Figure 1.

\section{Results and Discussion section}

The process of reducing air pollution in general for the operating conditions of the drying drum of brick plants in a general form can be mathematically described as follows: 


$$
P_{\mathrm{p}}=1-\left(1-P_{p 1}\right) \bullet\left(1-P_{p 2}\right)
$$

where: $\mathrm{Pp}$ is the probability of implementing the process of reducing dust air pollution; $\mathrm{Pp} 1$ is the probability of implementing the process of reducing the dust-forming ability of clay and inert additives as a raw material, or a drying drum as a process equipment; Pp2 is the probability of the implementation of the process of reducing air pollution.

The physical model we have proposed for the process of atmospheric dust pollution for the operating conditions of the drying drum of brick plants is used as the basis for constructing a physical model of the process of reducing air pollution for the considered production and technological conditions. The block diagram of the physical model of the process of reducing air pollution for the dryer drum reveals the relationship of the totality of sequentially and purposefully implemented stages of the second cycle of dust removal of the atmosphere and is presented in Figure 1.

According to the physical-energy concept used by us as a theoretical basis [11], the process of reducing dust pollution for the operating conditions of the drying drum of brick plants is considered to consist of two main cycles as an interconnected sequence of targeted actions by pre-prepared "additional" disperse systems on pollutant (inorganic dust with $\mathrm{SiO} 2$ content of 20-70\%) gradually trans-forming from the state of the "initial" dispersed system to "intermediate". In this case, the main goal of the corresponding stage of the process of reducing dust pollution under the considered production conditions is to reduce the content of particles of the dispersed phase in the pollutant, represented by inorganic dust with a $\mathrm{SiO} 2$ content of $20-70 \%$ and considered as the "initial", "intermediate" and "residual II-4" disperse systems. An analysis of the presented structural diagram of the physical model allows us to conclude that for the operating conditions of the drying drum of brick factories in the process of exposure to the polluting dust substance considered as the "initial" dispersed system, external "additional" dispersed systems prepared according to the corresponding parameters provide such change in the parameters of properties (PP), energy parameters (Wa) and stability (U) of the pollutant, which, ultimately, leads to its destruction as a disperse system. A graphical interpretation of such a transformation of dispersed systems, accompanied by a corresponding change in their aggregate stability in the process of reducing dust air pollution, is presented in Fig. 2.

Based on the presented structural diagram of the physical model and the conversion of dispersed systems in the process of reducing dust air pollution for the operating conditions of the drying drum of brick plants, we made a preliminary assessment of the feasibility and opportunity of implementing each of the considered cycles and the corresponding stages of the process of reducing dust air pollution in relation to the production and technological conditions of operation of the drying drum in brick factories. 


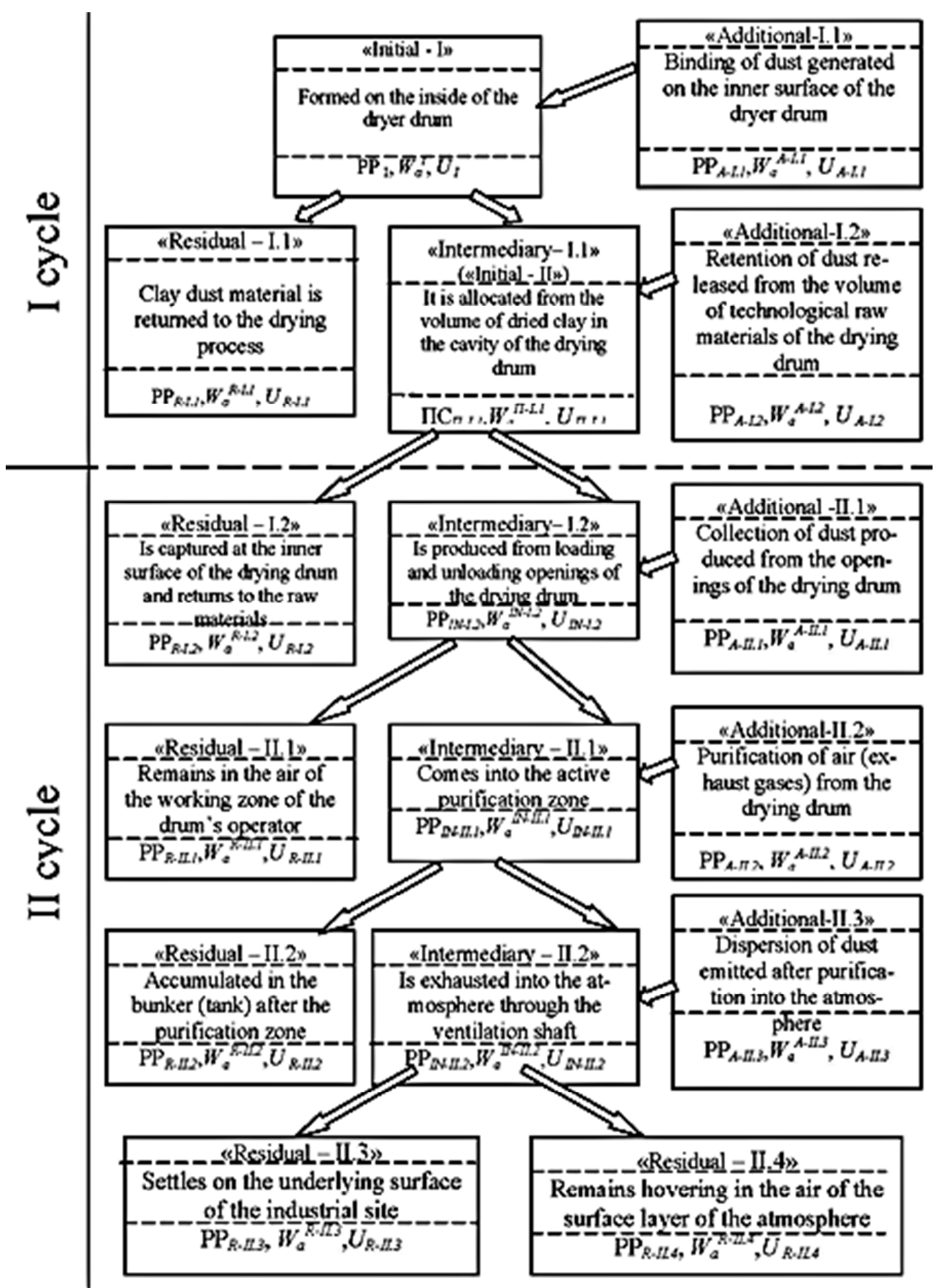

Fig.1. Block diagram of the physical model of the process of reducing dust air pollution for the operating conditions of the drying drum of brick factories

Let us analyze the possibility of use the corresponding stages of the first cycle: dust binding and dust retention.

Dust binding, considered as the first stage of the first cycle of the process of reducing dust air pollution, is usually organized on the basis of the use of a binder component, which 
is most often used in practice for various types of wetting-binding fluids with increased adhesive properties. The use of such liquids in the operating conditions of the drying drum on brick plants is not possible due to the rather high temperature values in the drum cavity. In these cases, intense evaporation of liquids used for dust binding may be observed. In addition, there are great difficulties associated with the supply of these liquids to the rotary drying drum. In addition to the above, this can lead to water logging of the processed clay and inert materials (technological raw materials), as well as to violation of the tempera-ture regime in the internal volume of the drum, which is unacceptable by operational and technological requirements. As a result, we can conclude that the organization of the binding stage in the considered production and technological conditions is not possible.

Dust retention, considered as the second stage in the implementation of the first cycle of the process of reducing dust air pollution, is usually organized on the basis of various screens, covers, shelters that limit the exit of the generated dust from the volume of processed technological raw materials. Analyzing the operating conditions of the drying drum of brick plants, it can be concluded that a special additional implementation of the retention of dust generated and released in the cavity of the drying drum of brick plants does not make sense, since the cylindrical body of the drying drum itself acts as a screening dust-holding shell. However, it should be noted that the loading and unloading openings of the drying drum remain open, which allow dust particles not trapped inside the cylindrical body to be released into the air of the working zone of the drying drum, and therefore into the air of the production premises.

As a result, we can conclude that in the production and technological conditions of operation of the drying drum of brick plants under consideration, the implementation of the first cycle of the process of reducing dust pollution of air is impractical.

Let us consider the feasibility and possibility of organizing during the operation of the dryer drum of brick factories of the second cycle of the process of reducing dust air pollution, which includes the following stages: dust collection, air (exhaust gas) dust removal and dust dispersal in the surface layer of the atmosphere.

The aerodynamic method of dust collection under the operating conditions of the dryer drum of a brick factory based on the organization of suction or blowing-in air flows in the technological units of the drying drum (near the loading and unloading holes) practically does not interfere with the organization and flow of the main technological process of drying, allows to remove dust particles directly from the zone of their emission and transport them to the zone of air purification (exhaust gases) from dust without introducing of other components into the drying cavity of the drum. Thus, it may well be used in the considered production and technological conditions.

An analysis of the features and main characteristics of the known methods for implementing the aerodynamic method of dust collection has allowed us to conclude that, in relation to the operating conditions of the drying drum of a brick factory, the most effective implementation of the aerodynamic method of collecting is possible by linear suction air flows (local suction), as well as linear suction-pumping air flow (activated local suction).

The hydrodynamic method of dust collection under the operating conditions of a dryer of a brick factory, based on the organization of a liquid stream in the form of droplets or bubbles in the technological units of the drying drum, can lead to excessive wetting of the processed clay and inert materials (technological raw materials), microclimate parameters in the working zone of the drying drum, adversely affect the operation of technological equipment by changing the temperature regime of the drying process, which is unacceptable technologically m requirements. Thus, the hydrodynamic method of capture is 
not applicable in the considered production and technological conditions.

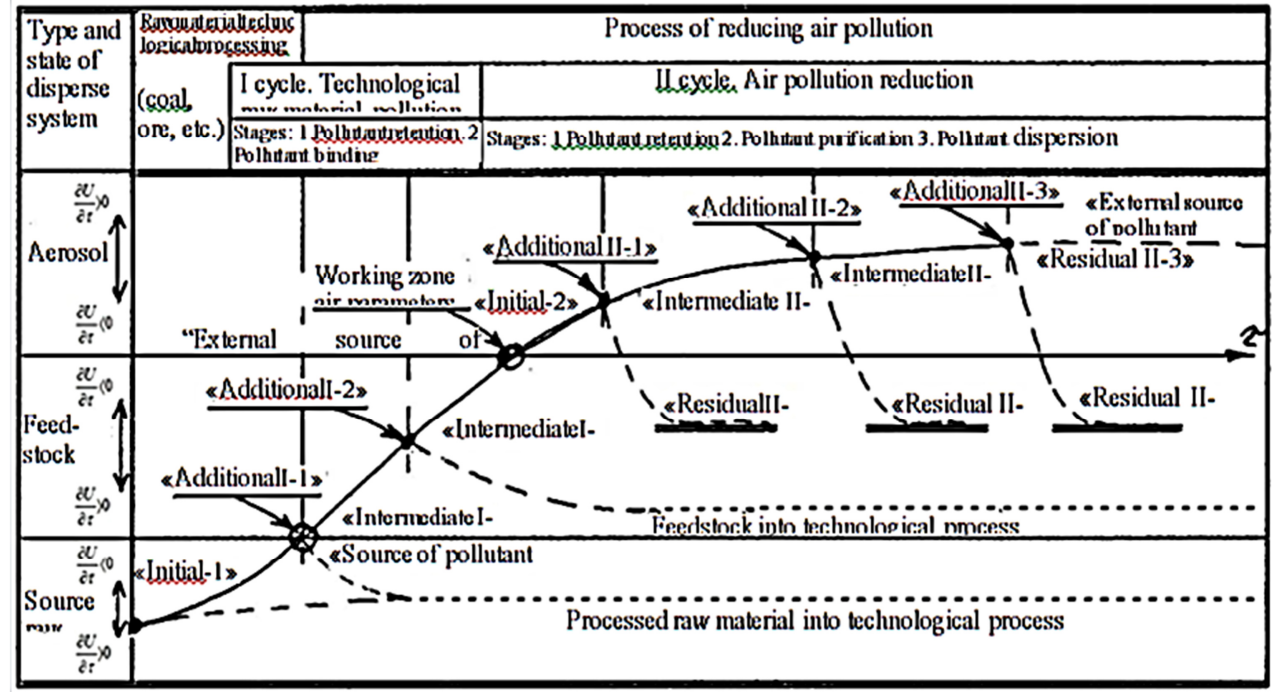

Fig.2. Transformation of dispersed systems in the process of reducing air.

Having carried out a similar analysis for the thermophysical and electromagnetic methods of dust collection, we concluded that they are also not applicable in the considered production and technological conditions, causing various negative effects on the drying process and on the state of the working zone of the drying drum.

The second stage of the second cycle, which is the purification of air (exhaust gases) from dust, in accordance with the classification scheme presented in Figure 1.3, can also be implemented by several methods. Our analysis, evaluation and selection of methods for air purification (of exhaust gases) from dust as applied to the operating conditions of the drying drum of brick plants allowed us to conclude the following.

The aerodynamic method of airpurification (exhaust gases) from dust under the conditions of operation of a drying drum of a brick factory, based on the organization of linear dust-gas-air flows in an isolated volume from the environment, does not affect the change in the basic physicochemical properties of dust particles emitted from the stream ensuring the possibility of their secondary use in the drying process.

The aerodynamic method of airpurification (exhaust gases) from dust under the conditions of operation of a drying drum of a brick factory, based on the organization of vortex dust-gas-air flows in an isolated volume from the environment, also does not affect the change in the basic physicochemical properties of dust particles emitted from the stream, providing the possibility of their secondary use in the drying process.

Having carried out a similar analysis for the hydrodynamic method of air purification (exhaust gases) from dust by low-pressure irrigation, high-pressure irrigation, pneumohydroirrigation and foam method, we concluded that they are also applicable for the efficient extraction of dust particles from a dust-gas-air stream before its discharge into atmosphere. However, in these cases, the secondary use of the sludge generated from dust particles in the drying process is possible only after its additional preliminary processing, which provides the required physicochemical properties of the secondary raw materials.

Considering the technological conditions of operation of the drying drum of brick factories when it is located in closed premises of the workshop and the impossibility of isolating it from the production air environment, we can conclude that for the considered 
production and technological conditions, the organization of the second cycle of the process of reducing dust air pollution should be the consistent implementation of two main stages: collecting dust particles in such structural zones of the drying drum where their intensive production is observed and subsequent purification from these particles in the dust collection process.

The process of air purification from dust for operating conditions of a drying drum of brick factories, the implementation of which is to prepare an "additional-II.2" dispersed system with the corresponding property parameters (PPA-II.2) can be considered effective in that case, when during exposure to "additional-II.2" dispersed system of a pollutant (inorganic dust with a $\mathrm{SiO} 2$ content of $20-70 \%$ ) as an "intermediate-II.1" dispersed system, not only the separation of dust particles (dispersed phase) and air (dispersion environment) in the "intermediate-II.1" system will be provided for, but also prevention of the residual content of the dispersed phase of the "additional-II.2" dispersed system in dust-free air exhaustedinto the atmosphere.

Ultimately, the process of air purification from dust generates two dispersed systems. Part of the dusty pollutant in the form of a "residual II.2" disperse system, which is dust particles extracted from a dusty air stream, as a dust material (sludge) should be sent either to secondary use in a techno-logical process with possible regeneration, or for disposal. Another part of the polluting dusty sub-stance, which we consider to be "intermediate-II.2" dispersed system, which is a residually dusty dust aerosol, should be directed to the atmosphere. At the same time, the "intermediate-II.2" disperse sys-tem characterized by stability or a slight increase in its aggregate stability should differ in the minimum content of dust particles (dispersed phase), ensuring compliance with maximum allowable maximum single concentration or maximum allowable mean daily concentration when released into the atmosphere. In general, the process of reducing dust air pollution for the operating conditions of the drying drum of brick plants can be considered effectively implemented if the above condition is met.

Discussion and conclusions. Having determined the main structure of the technology for organizing the process of reducing dust air pollution for the operating conditions of the drying drum of brick plants, it is necessary to go on to formalize the main resulting parameters of this process, which are widely used as efficiency and energy-energy index [12-14].

\section{Conclusions}

Having determined the main structure of the technology for organizing the process of reducing dust air pollution for the operating conditions of the drying drum of brick plants, it is necessary to go on to formalize the main resulting parameters of this process, which are widely used as efficiency and energy-energy index [12].

\section{References}

1. 2. A.B. Strelyaeva, N.S. Barikaeva, E.A. Kalyuzhina, D.A. Nikolenko, Bull. VolgGASU, 3(34), 11 (2014) http: //vestnik.vgasu.ru/attachments/StrelyaevaBarikaevaKalyzinaNikolenko-2014_3_34_.pdf

2. I.N. Logachev, K.I. Logachev, Boca Raton: CRC Press, 417 (2014)

3. L.A. Ostavnova, D.V. Tolstov, Mat. Int. Sci. Prac. Conf. You. Sci., 40-45 (2016)

4. N.Yu. Klimenti, O.S. Vlasova, M.A. Nikolenko, Bull. VolgGASU, 33 (52), 139-142 (2013) 
5. V. I. Bespalovб D. A. Protopopovaб Analysis of methodological approaches to the selection of dust-removing equipment when operating the power supply unit of an asphalt plant, Engineering Herald of the Don, (2012) https://cyberleninka.ru/article/n/analiz-metodicheskih-podhodov-k-vyboruobespylivayuschego-oborudovaniya-pri-ekspluatatsii-agregata-pitaniyaasfaltobetonnogo-zavoda.

6. V.I. Bespalov, N.S. Samarskaya, O.S. Gurova, E.P. Lysova, "Mod. Probl. Solute. Sci. Tran. Prod. Educ., Vol.2, Issue 2 (39), 80-85 (2015)

7. V.I. Bespalov, O.S. Gurova, N.V. Yudina, Improving the methods and means of dust removal of the air environment of concrete mixing departments of factories of reinforced concrete products and designs, Monograph (2015)

8. K. A. Belokur, Improvement of technology of dust removal of air of working zones of conveyor transport at the enterprises of the building industry, Abstract of dissertation for the degree of candidate of technical science (2007)

9. V.I. Bespalov, T.A. Tkacheva, Mat. Int. NPK "Construction-2005", 149-151 (2005)

10. I.V. Bespalov, S.O. Gurova, N. S. Samarskaya, E. P. Lysova, In «Biosciences, BiotechnologyResearchAsia», Vol.11, No 3, 1615-1620 (2014)

11. V.I. Bespalov, A.V. Konovalov, A.N. Kabarukhina, Fund, Appl, Iss, Sci, Educ, 2, 7-8 (2016)

12. V.I. Bespalov, T.A. Khezhev, O.N. Paramonova, Mag, "Scie, Rev," No. 6, 28-30 (2016) 